\title{
Development of a Living Lab for a Mobile-Based Health Program for Korean-Chinese Working Women in South Korea: Mixed Methods Study
}

Youlim Kim ${ }^{1}$, MPH; Hyeonkyeong Lee ${ }^{2}$, PhD; Mi Kyung Lee ${ }^{1}$, MPH; Hyeyeon Lee ${ }^{1}$, MPH; Hyoeun Jang ${ }^{1}$, MS

${ }^{1}$ College of Nursing, Yonsei University, Seoul, Republic of Korea

${ }^{2}$ Mo-im Kim Nursing Research Institute, College of Nursing, Yonsei University, Seoul, Republic of Korea

\section{Corresponding Author:}

Hyeonkyeong Lee, $\mathrm{PhD}$

Mo-im Kim Nursing Research Institute, College of Nursing

Yonsei University

50-1 Yonsei-ro

Seodaemun-gu

Seoul, 03722

Republic of Korea

Phone: 82222283373

Fax: 8223925440

Email: hlee39@yuhs.ac

\begin{abstract}
Background: Korean-Chinese (KC) women make up the largest group of female migrants in South Korea. To prevent and manage chronic diseases in middle-aged $\mathrm{KC}$ women working full time, it is necessary to develop health promotion programs that utilize an online platform because such a platform would allow individuals to participate in health promotion interventions at their convenience.

Objective: This study aimed to develop a living lab for a mobile-based health (LLm Health) program focused on improving the physical activity and cultural adaptation of $\mathrm{KC}$ women workers.

Methods: We used a mixed methods design. Living lab principles were factored into the LLm Health program, including the use of multiple methods, user engagement, multistakeholder participants, real-life settings, and cocreation. The program was developed using the 4 steps of the intervention mapping method: needs assessment, setting of objectives, identification of intervention strategies, and intervention design. Needs assessment was conducted through a literature review, focus group interviews with a total of 16 middle-aged $\mathrm{KC}$ women, and an online survey related to health promotion of migrant workers given to 38 stakeholders. KC middle-aged women participated in the early stages of program development and provided the idea of developing programs and mobile apps to enhance physical activity and acculturation. The mobile app developed in the program was validated with the help of $12 \mathrm{KC}$ women and 4 experts, including 3 nursing professors and a professor of physical education. They were asked to rate each item based on content, interface design, and technology on a 4-point scale using a 23-item Smartphone App Evaluation Tool for Health Care.
\end{abstract}

Results: The LLm Health program comprised a 24-week walking program using Fitbit devices, the mobile app, and social cognitive interventions. The mobile app contained 6 components: a step counter, an exercise timer, an online chat function, health information, level of cardiovascular risk, and health status. The cultural aspects and lifestyles of $\mathrm{KC}$ women were accommodated in the entire process of program development. The content validity of the mobile app was found to be 0.90 and 0.96 according to the $12 \mathrm{KC}$ women and 4 experts, respectively.

Conclusions: The mobile app was found to be valid and acceptable for $\mathrm{KC}$ women. The living lab approach was a useful strategy for developing a culturally adaptive LLm Health program for $\mathrm{KC}$ women workers, leading to their active participation in the overall research process, including needs assessment, program composition, and pre-evaluation.

(JMIR Mhealth Uhealth 2020;8(1):e15359) doi: 10.2196/15359 


\section{KEYWORDS}

mHealth; living lab; intervention mapping; health promotion

\section{Introduction}

\section{Background}

Migrant workers have health disparities because of language, cultural barriers, and difficulty accessing medical services [1] and are categorized as a vulnerable group in terms of health care access and treatment [2]. In particular, a study of Korean-Chinese (KC) migrant workers in South Korea showed that the percentage of $\mathrm{KC}$ workers with poor perceived health was higher than that of native Koreans [3].

KC migrants make up almost $31 \%$ of all migrants in South Korea, with a total population of about 680,000 . Moreover, $70.4 \%$ of $\mathrm{KC}$ women are middle-aged [4]. The most common health issues among middle-aged $\mathrm{KC}$ women residing in South Korea are musculoskeletal symptoms, depression, cultural adaptation stress, and cardiovascular risk factors (obesity, hypertension, and diabetes) [5,6]. As middle-aged women make up such a large proportion of $\mathrm{KC}$ migrants and are experiencing a profound health transition because of menopause, health promotion interventions targeting this group in particular should be developed and delivered in an accessible manner.

Physical activity is highly recommended for health promotion among middle-aged individuals [7]. Previous studies have shown that walking for about $30 \mathrm{~min}$ per day for 5 days a week is effective for reducing the risk of cardiovascular disease [8,9]. It may also help prevent musculoskeletal disorders by reducing joint pain and enhancing muscle strength [10].

Therefore, walking exercise may be an effective intervention for addressing the primary health problems of $\mathrm{KC}$ women workers. However, although women tend to recognize that a lack of physical activity is a health risk factor, their actual exercise practice remains low [7]. KC women reported that it is difficult to maintain regular exercise because of a lack of time, motivation, and social support or an unfamiliar working environment [11]. To ensure the sustainability of physical activity promotion programs, and thereby maximize their benefits for disease prevention and health promotion, these programs should be both culturally acceptable and easily accessible for $\mathrm{KC}$ women. Given the aforementioned barriers, on-site exercise programs may be inappropriate for $\mathrm{KC}$ women workers; home-based or mobile-based interventions seem most suitable, as they can be delivered at a convenient time and place. There is evidence for their efficacy: coaching using SMS (including feedback and facilitation) and app-based health promotion programs aimed at facilitating communication between participants and providers have been found to contribute to improved health performance in various community-dwelling populations [12,13].

In South Korea, almost $91 \%$ of the population uses smartphones. Smartphone users install more apps than users of other types of mobile device [14]. Moreover, $88 \%$ of migrant workers in Seoul have smartphones [15]. In accordance with the high rates of smartphone and app usage, mobile health (mHealth) has been rapidly gaining attention in the field of health promotion. Researchers have defined mHealth as the use of various apps, such as GPS and Bluetooth technology, as well as the basic utilities (voice calling, SMS) of mobile or wireless devices for the purposes of health and health care [16]. Mobile-based interventions are increasingly being adopted to increase migrants' access to health services. Such interventions have proven useful for expanding information provision and peer and resource support [17-19].

For exercise interventions to be effective for migrants, activities should be tailored to their particular level of experience and demands. One approach to ensuring such tailored interventions is a living lab. In a living lab, participants and stakeholders conduct research to best represent their needs; it is an innovative activity in which users and stakeholders all actively participate in the research process, even while at home, for the betterment of community problem solving or services [20]. In an integrative review study [21], the living lab approach was identified as an appropriate way to identify and address the health needs of vulnerable groups for whom health care services are economically and locally less accessible. The living lab approach is useful for developing culturally specific health promotion programs centered on $\mathrm{KC}$ women through the application of its core principles, namely, user participation, the use of multiple methods, stakeholder participation, basis in real-life settings, and cocreation.

\section{Objectives}

The purpose of this study was to apply the living lab approach to $\mathrm{KC}$ women (who are, in this context, the users) to enable their direct participation in the development of a culturally sensitive mobile app-based health promotion program (living lab for a mobile-based health [LLm Health]), alongside community stakeholders. We hope that the program will help contribute to the health promotion activities of middle-aged KC women and establish a culture of health promotion in the community.

\section{Methods}

\section{Overview}

This study used a mixed method design to develop a mobile app-based health promotion program using the living lab approach [22]. Living labs emphasize a multimethod approach, user engagement, multistakeholder participants, real-life setting, and cocreation. In this study, the process of program development was, through the intervention mapping approach [23], as follows: needs assessment, setting of objectives, identification of intervention strategies, and intervention design. This study was approved by our institutional review board (IRB-2017-1641-001).

\section{Needs Assessment}

The needs assessment comprised a literature review, focus group interviews, and a stakeholder analysis. 


\section{Literature Review}

We searched the PubMed, EMBASE, and CINHAL databases for studies published in English up to November 2017. The search terms were "mobile applications and health promotion" OR "smartphone applications AND health promotion" OR "app-based intervention AND health promotion." We ultimately analyzed 12 out of 191 studies, after excluding those that did not meet the criteria. More specifically, we considered only the studies on health interventions for adults in peer-reviewed journals, having excluded studies that used only SMS text messaging or Web-based interventions.

\section{Focus Group Interviews}

The focus group interviews were conducted between November and December 2017. A total of 3 interviews were conducted with 16 middle-aged $\mathrm{KC}$ women; each interview lasted between 60 and $90 \mathrm{~min}$. The participants were from Seoul and Gyeonggi-do, aged between 40 and 65 years, had been working full time for the last 6 months, were able to communicate in Korean, understood the purpose of the study, and agreed to participate. The interviews were conducted in a church education center in the $\mathrm{K}$ district of Seoul, which has a large population of KC women. The interviews were carried out by researchers trained in conducting focus group interviews.

The focus group guideline was developed by the researchers according to the guidelines of Krueger and Casey [24]. Before each interview, participants were informed of the necessity of the research, its purpose and methods, that the data would be anonymous, and that they could withdraw from the interview at any time. The questions asked in the interviews focused on the health information necessary for health promotion of $\mathrm{KC}$ women workers and the difficulty of adapting to everyday life as a foreign worker. The interviews were recorded and transcribed and then subjected to content analysis. A researcher repeatedly read the transcripts; identified and verified meaningful words, sentences, and paragraphs; and categorized them into themes.

\section{Stakeholder Analysis}

An online questionnaire was conducted for the stakeholder analysis, from November to December 2017. In total, 38 people were surveyed as community stakeholders, including those in national institutions (public health centers), local community organizations (Korean support center for foreign workers and $\mathrm{KC}$ church), KC merchant society (Koreans who employed KC women), and $\mathrm{KC}$ women who participated in the focus group interview. We provided the survey participants with the same information on the study that we provided to the focus group participants (eg, necessity, purpose, and anonymity of data) via SMS text message and obtained their voluntary consent to participate. Stakeholders were provided a URL to the online survey system at the bottom of the explanation comment sent by email. To protect the rights of the participants, the purpose and procedures of the research, privacy protection, and withdrawal from research participation were presented on the start screen before they began the online survey. The online survey was set up so that the survey would proceed step by step only if participants agreed to participate in the survey. The participants completed the online questionnaire, which included 10 items, each rated on a 5-point Likert scale, evaluating the health promotion of migrant workers in terms of interest, importance, influence, and position of stakeholders. The data obtained through the online questionnaires were assigned IDs and stored in an encrypted computer, accessible only to researchers trained in research ethics.

The collected data were analyzed using the Beeye of stakeholder analysis tool.

\section{Settings of Objectives}

The LLm Health program was based on the Interaction Model of Client Health Behavior (IMCHB) by Cox [25]. There are 3 main elements of Cox's IMCHB: client singularity, client professional interaction, and health outcome. Cox considered that the individual characteristics of subjects, including their socio-psychological factors, are necessary to understand their practice of positive health behaviors, and emphasized the importance of interaction between the participant and provider in determining health behaviors. The element of client singularity is determined by background variables, internal synchronization, cognitive appraisal, and emotional responses. The element of client professional interaction is determined by emotional support, health information provision, decision control, and professional and technical competence. Finally, the element of health outcomes included the use of health care services, clinical health status indicators, health problem severity, and service satisfaction. In this study, we designed various social cognitive interventions that considered the cultural characteristics of participants for inclusion in the LLm Health program. We then examined the effects of intervention on health outcomes to compare the enhanced group with the control group.

\section{Identification of Intervention Strategies}

In this study, we decided on intervention strategies using the behavior change technique (BCT) taxonomy of Michie et al [26]. This taxonomy describes 40 BCTs that have proven effective in producing behavior change, through an analysis of previous studies on behavior change interventions. This strategy is based on a variety of social psychological theories, including social cognitive theory. The main contents of BCTs involve providing information related to the results of the health behavior, setting goals, self-monitoring, overcoming obstacles, feedback, and social support.

\section{Intervention Design}

The LLm Health program was designed to improve the physical activity and cultural adaptation of KC middle-aged women workers. The program consisted of 12-week adaptation and 12-week maintenance phases. Enhanced intervention was designed to strengthen social-cognitive factors related to physical activity for the adaptation phase only. The mobile app was a core intervention tool used through the 24-week period by the participants.

\section{Development of the Mobile App}

A total of 10 meetings were held with app developers from November 2017 to February 2018. The mobile app was designed to measure the number of steps and exercise duration of users 
using smart bands, and we attempted to encourage users to self-monitor their walking adherence through the development of a mobile app linked with the smart bands (Fitbit Alta). The app was designed for the Android operating system based on the resolution of a Samsung Electronics Galaxy S5. Data, such as the number of steps and exercise duration of participants wearing the smart bands, were collected by the app from the
Fitbit company server. These data were sent to the mobile app "Health Club" and linked with the administrator Web page for the research team. The data transmission process is shown in Figure 1. To develop a mobile app that suited the participants, we referred to the findings of the needs assessment. Moreover, we consulted with $\mathrm{KC}$ participants for help designing the app, color, and logo from the initial development process.

Figure 1. The process of mobile app development.

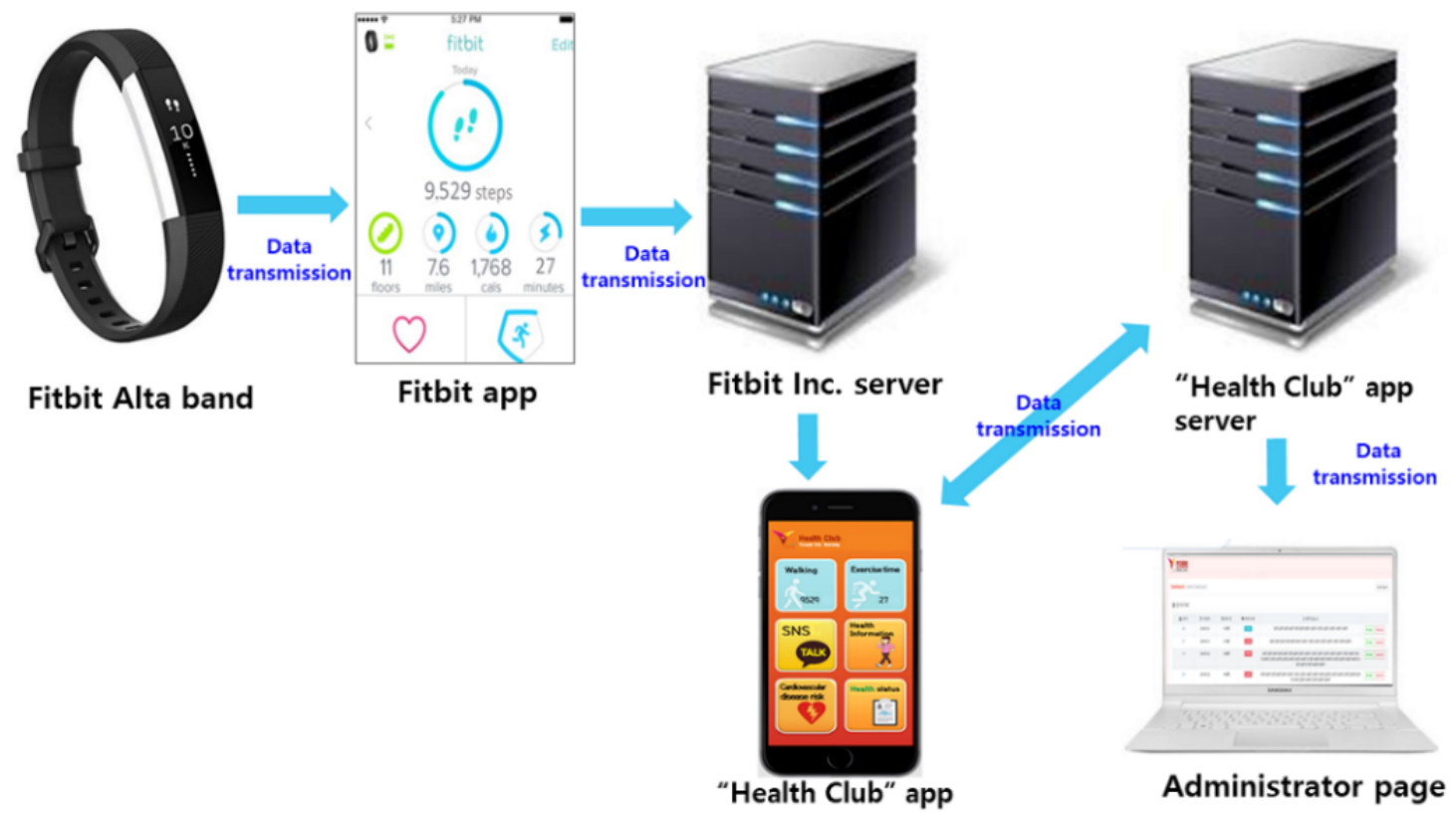

\section{Validity Test of the Mobile App}

The app was evaluated using the Smartphone App Evaluation Tool for Health Care [27], which contains 23 items in 7 domains: content (accuracy, understanding, and objectivity), interface design (consistency, design suitability, and vocabulary accuracy), and technology (security). Each item was rated on a 4-point Likert scale. The content validity of the app was also evaluated based on the recommendations of at least three experts [28]—-specifically, 3 nursing professors with multicultural research experience and a professor of physical education. The content validity was deemed appropriate if the average of the scale-level content validity indexes (the ratio of responders who rated an item with 3 or 4; Scale Content Validity Index/Average) was 0.90 [29].

\section{Development of the Enhanced Intervention}

The 24-week period was divided into a 12-week adaptation period for providing an intervention and a 12-week maintenance period without the intervention. During the 12-week adaptation period, the following interventions were applied to strengthen the social psychological factors affecting the change in health behavior and social-cognitive capabilities (self-efficacy, social support, etc) of the enhanced treatment group: sending SMS to improve self-efficacy, setting exercise goals, providing feedback, and social networking service (SNS) interaction. In addition, a photovoice activity was planned to represent the exercise promotion factors of community and the sense of local community that $\mathrm{KC}$ participants perceive.

The self-efficacy SMS was constructed according to the questionnaire items of the Barrier Self-Efficacy Scale of McAuley et al [30] and the self-efficacy tool of Marcus et al [31].

To help acculturation, offline cultural workshops were planned to provide information about Korean life according to the needs of $\mathrm{KC}$ women.

\section{Results}

\section{Needs Assessment}

\section{Literature Review}

According to the 12 studies on mobile app-based health promotion programs, the primary goals of these programs were physical activity promotion, weight and diet management (8 studies), and establishment of a healthy lifestyle (4 studies). The primary purposes of the apps in these studies were to provide feedback on personal health status ( 9 studies), behavior change monitoring ( 9 studies), and health information provision (8 studies). Overall, the mobile app-based interventions for adults without disease were found to be effective for improving health promotion behavior [32].

\section{Focus Group Interviews}

The analysis of the focus group interviews of middle-aged KC women workers identified the following main topics related to their health management: nutrition management (nutrient proportion and calorie confirmation method), information about chronic diseases, and exercise methods at home. These were, 
therefore, selected as contents of the LLm Health program. KC women workers also expressed the need for education related to cultural discrimination, such as nonpersonal treatment because of cultural differences in South Korea, the need to learn a newly coined term, and their language restrictions in using English and foreign words. In addition, we confirmed that $\mathrm{KC}$ women actively seek health information using smartphones and share this information through online interactions.

\section{Stakeholder Analysis}

Analysis of the stakeholder questionnaire data revealed that the type of participation desired by most stakeholders was a partnership $(n=20)$ in program planning, implementation, and evaluation. Offline health education $(n=19)$, app-based health promotion information $(\mathrm{n}=11)$, health information booklets $(n=6)$, and cultural competence training for community practitioners $(n=6)$ were also noted as helpful activities in designing health promotion programs for migrant workers. An analysis revealed that stakeholders from national institutions, local community organizations, and $\mathrm{KC}$ women in Korea were highly influential and interested in health promotion of foreign workers, whereas Korean employers showed little interest in it (Figure 2).

Figure 2. Stakeholder analysis: interest and influence.

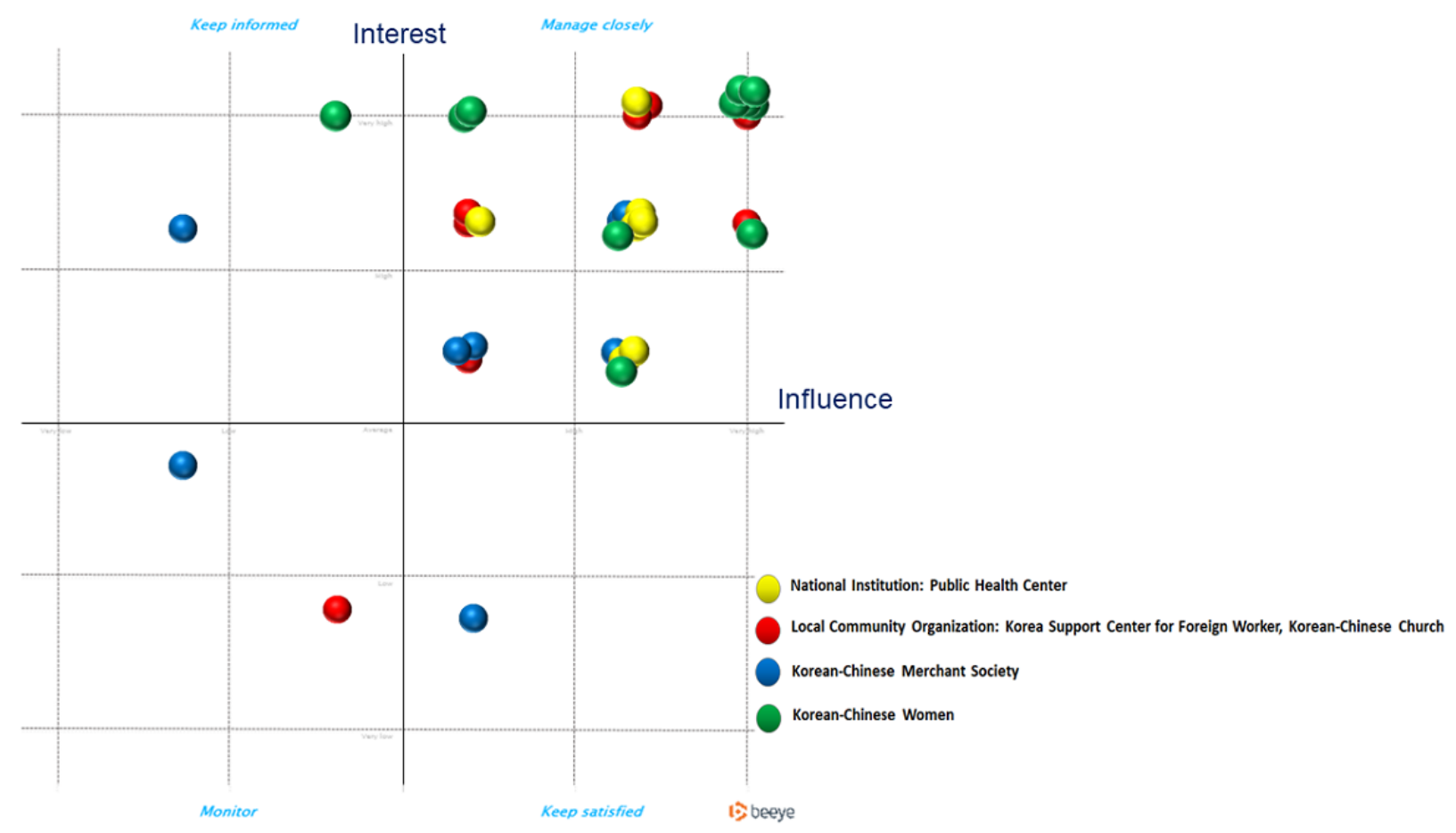

\section{Setting of Objectives}

Drawing on the IMCHB of Cox [25], we designed the interaction elements of the participants and experts in the LLm Health program. We decided to deliver health information through health booklets and exercise skills coaching. We used SMS text messages to encourage participants and to motivate them to continue the program as a form of emotional support. Decision control was established by enabling users to identify and implement step-by-step goal setting and monitor the results of follow-up tests in the app. Participants were also encouraged to apply the health information acquired in the offline cultural workshops in their daily life. We ensured access to expertise and technical ability by having the research team be available for counseling regarding the results of participants' health tests and by providing participants with information on improving and preventing cardiovascular diseases. These interventions were expected to help participants achieve social-cognitive competence (eg, exercise self-efficacy, social support, and community consciousness), leading to an increase in walking adherence.

\section{Identification of Intervention Strategies}

In this study, we applied the BCT taxonomy of Michie et al [26] to the adaptation period (12 weeks after participation in the program) in the enhanced treatment group to strengthen self-efficacy and social support for exercise performance (Table 1). Self-monitoring of walking adherence was encouraged by providing participants with walking exercise results and through goal setting. In addition, a photovoice intervention was employed to overcome obstacles to exercise and to identify promotive factors using community resources (eg, parks and sports facilities). To encourage cultural adaptation in participants, we provided useful information about life in South Korea. In offline cultural classrooms, participants were encouraged to announce their willingness to practice the contents of education and encourage each other to induce positive behavior changes. Finally, we designed a strategy to provide personal counseling on the results of health exams and to provide nursing prescriptions for lifestyle improvement. 
Table 1. Behavior change theory methods and practical strategies for the living lab for a mobile-based health program.

\begin{tabular}{|c|c|c|}
\hline Determinants & Behavior change technique methods & Strategies \\
\hline Exercise adherence & $\begin{array}{l}\text { Prompt review of behavioral goal behavior modeling; prompt specific } \\
\text { goal setting; set graded tasks; prompt self-monitoring of behavior; provi- } \\
\text { sion of feedback on performance }\end{array}$ & $\begin{array}{l}\text { Setting step goal ( } 3 \text { times); sending a medal image } \\
\text { ( } 3 \text { times); guiding in possible muscular and } \\
\text { stretching exercises indoors }\end{array}$ \\
\hline Social support & $\begin{array}{l}\text { Setting graded tasks; prompt specific goal setting; environmental restruc- } \\
\text { turing; social support; provide general encouragement; prompt self-talk }\end{array}$ & $\begin{array}{l}\text { Setting goal of walking steps ( } 3 \text { times); sending } \\
\text { medal image ( } 3 \text { times); photovoice; SNS }{ }^{\mathrm{a}} \text { interac- } \\
\text { tion }\end{array}$ \\
\hline Self-efficacy & Prompt intention formation; environmental restructuring; social support & Exercise self-efficacy SMS (12 times) \\
\hline Sense of community & $\begin{array}{l}\text { Environmental restructuring; social support; provision of general encour- } \\
\text { agement; prompt self-talk }\end{array}$ & Photovoice; SNS interaction \\
\hline Acculturation & Use of imagery; provision of general encouragement; prompt self-talk & $\begin{array}{l}\text { Cultural adaptation contents ( } 6 \text { times); offline cul- } \\
\text { tural workshops ( } 3 \text { times) }\end{array}$ \\
\hline Health outcome & Provision of general information on behavior & $\begin{array}{l}\text { Personalized face-to-face counseling after health } \\
\text { examination }\end{array}$ \\
\hline
\end{tabular}

${ }^{\mathrm{a}}$ SNS: social networking service.

\section{Design of Intervention}

\section{Mobile App "Health Club"}

The developed mobile app was named "Health Club." In the cocreation process of the "Health Club" mobile app, the first task for $\mathrm{KC}$ women and stakeholders was to give the mobile app a name that could be easily understood and suitable for $\mathrm{KC}$ women. Simple and familiar terms were chosen as better than those that were less familiar. Consequently "Health Club" was selected over "Healthy Program" or "Healthy Heart." In addition, the researchers and $\mathrm{KC}$ women jointly reviewed and revised the mobile app menu design and health topics of interest, giving due consideration to $\mathrm{KC}$ women's preference and lifestyles.

Users could search for and download it from the Google Play Store after registering with a Google email address. To encourage participation in the study, we set up automatic transmission of Fitbit Alta data and Health Club app synchronization notifications once a day on the registered participants' mobile phones.

The app had 6 main functions, all listed on the main screen: number of walking steps, duration of exercise, chatting, health information, cardiovascular disease risk, and health status. The daily number of steps and moderate-intensity exercise time were obtained via synchronization with the Fitbit Alta, and participants were able to input their strength exercise and stretching time during the day. The group chat feature of the app was linked to an SNS (eg, KaKao talk) to encourage information sharing among participants, leading to an increase in emotional and network support. The health information covered 12 topics, including cardiovascular disease, musculoskeletal disease, menopausal symptoms, aging prevention, stress management, pharmacy and hospital available on weekends, weight control, healthy eating, stretching, strength exercise, and cancer screening for women. This information could be accessed as a PDF file or by linking users to related websites when participants pressed the relevant information icon.

Users' 10-year cardiovascular risk was calculated using an algorithm presented in the Framingham Heart study [33]; it was assessed at baseline and at 12- and 24-week blood tests. The health status menu was designed to check changes in health test results 3 times (baseline, 12 weeks, and 24 weeks) using numerical data and graphs (Figure 3). 
Figure 3. Components of the Health Club mobile app.

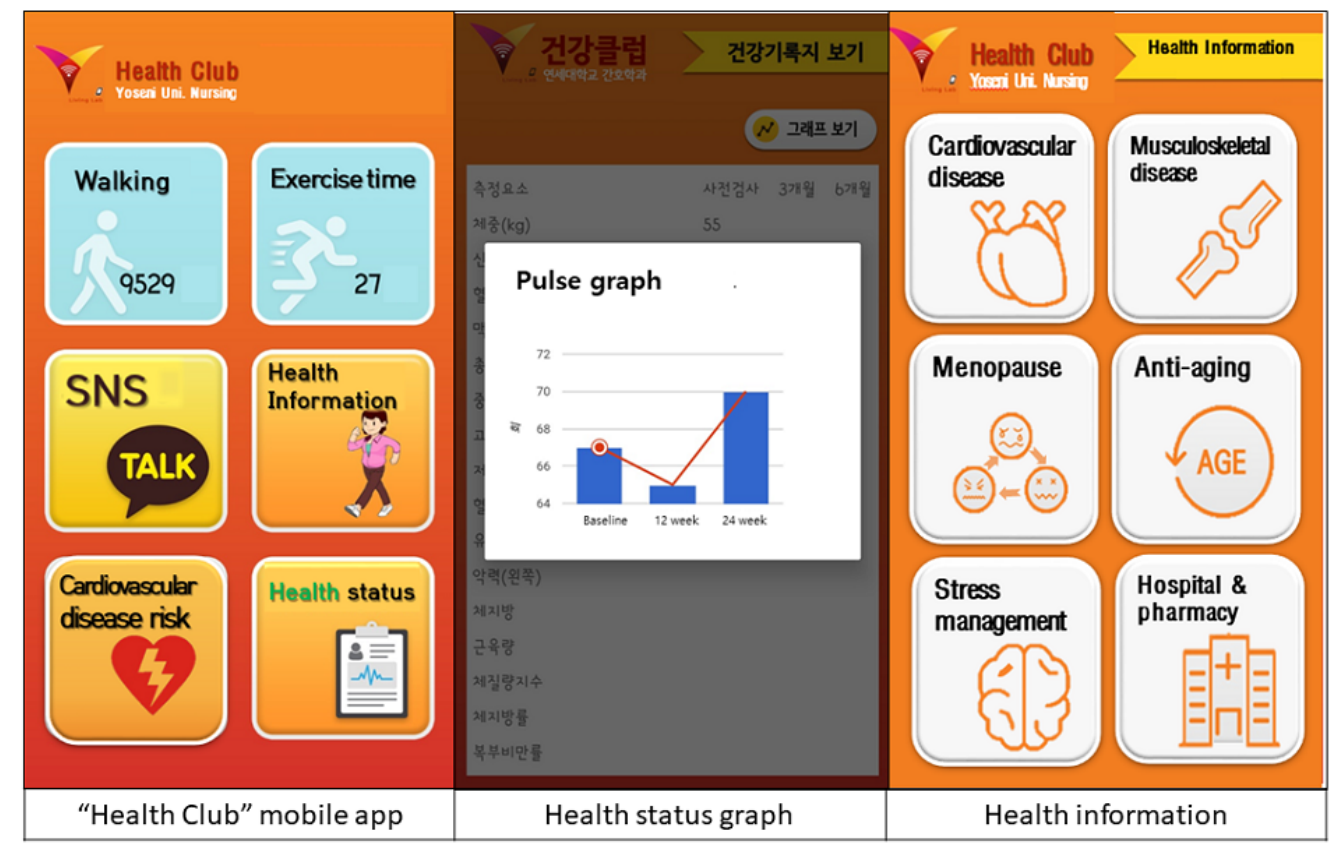

\section{Pilot Test of the Mobile App "Health Club"}

After developing the "Health Club," we recruited $12 \mathrm{KC}$ middle-aged women for a pilot test of its usability. They were selected as health leaders and were provided with educational materials, the mobile app, and a smart band to play a promotional role in recruiting participants in the following research. After health leaders used the Health Club app for 2 weeks, they were given the app evaluation tool. The content validity of the app was found to be 0.90 according to the $12 \mathrm{KC}$ women. The validity based on responses of the 4 experts to the mobile app was 0.96 .

The validity of 7 subitems evaluated by 4 experts and $12 \mathrm{KC}$ middle-aged women were as follows: accuracy $=0.90$, understanding $=0.91$, objectivity $=0.92$, consistency $=1$, design suitability $=0.96$, vocabulary accuracy $=0.98$, and security $=0.86$. The mobile app was revised and supplemented to reflect opinions on "adding the source of the information" and "adding statements regarding user privacy protection."

\section{Enhanced Intervention}

To encourage exercise adherence during the 12-week adaptation period, step goals were set 3 times every 4 weeks, and encouragement with a medal image was sent via SMS whenever participants reached the goal. The app was designed to send a self-efficacy SMS once a week, so that participants could overcome the barriers to exercise and recognize the benefits of exercise. A total of 12 self-efficacy SMS messages were designed, all with less than 60 characters that focused on mood, lack of time, lack of interest, physical discomfort, lack of social support for exercise, limitations because of appearance, limitations of place, fatigue, lack of exercise skills, negative perception of migrant worker exercise, and lack of awareness regarding the benefits of exercise.
The offline cultural classes covered 3 topics: "personal color and makeup," "low sodium healthy diet," and "practical English." These classes emphasized what users could do in real life, and individuals shared their action plans at the end of each class. To confirm the motivational factors and sense of community, participants were encouraged to post 2 pictures taken on the themes of "good exercise in our neighborhood" and "exercise experience with local people" using photovoice.

\section{Discussion}

\section{Principal Findings}

This study developed a culturally appropriate mobile app-based health promotion program for $\mathrm{KC}$ women by applying the living lab principles, entitled "LLm Health program." We also incorporated BCTs [34], which are based on the social cognitive theory of changing health behaviors, as main components of the health promotion program. The app was developed based on the characteristics of $\mathrm{KC}$ women-who often experience social isolation [35] and social and cultural challenges (eg, language barriers, changes in socioeconomic status, and emotional difficulties with loneliness and belonging) because of their international migration - to enable them to easily access health information and social support. The Fitbit Alta is a device that can be worn on the wrist by $\mathrm{KC}$ women who work in the household and service industries; it allows participants and researchers to monitor real-time exercise adherence.

\section{Implications}

This study is meaningful in that it is the first to apply the living lab approach in the migrant population. The participants were involved in the early stages of program development, proposing ideas for promoting physical activity and cultural adaptation. We believe that participants' acceptance of the program was enhanced through their participation in deciding the app name, 
interface design, contents, etc. Moreover, some $\mathrm{KC}$ women were selected as community health leaders, who voluntarily participated in the overall research process including program composition, pre-evaluation, and leading living lab-based active participation and cocreation. Through this study, we have involved various community stakeholders, including national institutions and religious facilities, in planning, development, and the implementation of this migrant health promotion program. According to previous studies, the participation of various stakeholders, such as health and welfare agencies, hospitals, clinics, companies, patient associations, and local governments, has been found to be a successful strategy for developing a patient-centered health management model for patients with chronic conditions [36]. In community-based health research, living labs appear to be useful for promoting active health behavior changes, especially among vulnerable social groups who often need to solve their health problems on their own [21]. The LLm Health program was designed to improve middle-aged KC women's self-efficacy and social support in relation to physical activity, as well as promote their physical, mental, and social health, while considering their specific cultural features. The living lab approach was applied as a platform to help these women solve their health problems by reflecting on their own point of view. In future research, it would be useful to incorporate the living lab principles into existing behavior change theories.

The main component of the LLm Health program was its use of BCTs. Previous studies have found that BCTs can promote the active participation of the vulnerable population. For instance, Sidhu et al [37] applied BCTs to improve the self-management ability of low-income individuals of various races with chronic conditions in the United Kingdom. Mathews et al [38] developed a type 2 diabetes prevention program for low-income individuals in India using BCTs at the individual, interpersonal support, and community levels. A therapeutic intervention using BCTs-primarily goal setting and social support-was an effective strategy for people from low social and economic backgrounds to engage in health promotion behavior [34]. We also applied goal setting [39] (setting a goal for the average number of steps every 4 weeks) in the LLm Health program, as it is well known to help reduce physical activity withdrawal and increase adherence. Developing health programs based on BCT to enhance the capacity of social-cognitive factors, such as the health information provision and SNS interaction used in this study, might be useful in planning effective intervention strategies for groups with different cultural and social backgrounds.

Although this study adopted several BCTs from the list of commonly used BCTs, such as goal setting and behavior modeling used in top-ranked physical activity apps [40,41], it is necessary to thoughtfully consider further BCTs that have been found to be effective for behavior changes in migrant populations.
This study developed a mobile app-based health promotion program that considers the characteristics of middle-aged $\mathrm{KC}$ women. Programs to promote migrants' participation in physical activity should consider the cultural beliefs and constraints of the participants [42]. Middle-aged KC women living in South Korea often live in low-income areas. Moreover, they have poor access to systematic health services [3] or good quality health care and tend to have difficulties with the early detection of illness [5]. They comprise a "culturally and linguistically diverse" population group [43] and experience considerable stress in adapting to Korean society [5]. High acculturation stress is associated with lower physical activity [44]; conversely, efforts to acculturate migrants can positively influence their physical activity levels [45]. It is, therefore, essential to consider the cultural aspects and lifestyles of immigrants when developing intervention programs so that they can best adapt to their new cultures.

From the perspective of convenience-particularly considering that $\mathrm{KC}$ women often perform housework and are employed in the service industry - our program relied on data from smart bands (Fitbit Alta), wearable devices that synchronized with the app to allow participants to check their exercise progress directly. Being able to constantly monitor their exercise might have increased their motivation to adhere to the exercise. The use of a smart band, which records objective real-time step counts and moderate-to-vigorous physical activity, overcomes the limitation of a previous study [46] measuring the effects of walking exercise, which relied on self-reported step counts.

This study has several limitations. First, owing to budget constraints, we could not develop an iPhone operating system version of the mobile app; it is only available on the Android operating system. Second, to enable examination of the effect of walking exercise on health, objective data on the number of steps and moderate-to-vigorous intensity exercise time were collected through the Fitbit Alta. However, there is limitation in that strength exercise and stretching had to be self- reported. Third, further efforts are necessary to educate middle-aged $\mathrm{KC}$ women on the terminology and technical aspects of wearable and mobile devices, to increase their ease of use. Therefore, it is essential to repeatedly train users in adopting a new technology during the initial adaptation stage.

\section{Conclusions}

We developed a mobile app-based program for the health promotion of middle-aged $\mathrm{KC}$ women using the living lab approach, which focuses on expanding participation and strengthening community health capabilities. This approach appears to be useful for creating health promotion program content and intervention strategies. It is recommended that future research examines the effectiveness of mobile app-based health promotion programs on physical and mental health outcomes for $\mathrm{KC}$ women. 


\section{Acknowledgments}

This work was supported by a grant from the National Research Foundation of Korea, which was funded by the Korean government (Ministry of Science, ICT and Future Planning; NRF-2017R1A2B4008671). The authors would like to thank the Korean Support Center for Foreign Workers for their cooperation.

\section{Conflicts of Interest}

None declared.

\section{References}

1. Moyce SC, Schenker M. Migrant workers and their occupational health and safety. Annu Rev Public Health 2018 Apr 1;39:351-365. [doi: 10.1146/annurev-publhealth-040617-013714] [Medline: 29400993]

2. Grabovschi C, Loignon C, Fortin M. Mapping the concept of vulnerability related to health care disparities: a scoping review. BMC Health Serv Res 2013 Mar 12;13:94 [FREE Full text] [doi: 10.1186/1472-6963-13-94] [Medline: 23496838]

3. Chung K, Kim S, Ko J, Lee K, Lee H, Lee C. Survey on living conditions of foreign workers. Gyeonggi-do: Korea Immigration Service, Ministry of Justice; Dec 2013:1-747.

4. KOSIS KOrean Statistical Information Service. Korea Immigration Service Statistics 2017 URL: http://kosis.kr/statisticsList/ statisticsListIndex.do?menuId=M $01 \quad 01 \& \mathrm{vwcd}=\mathrm{MT}$ ZTITLE\&parmTabId=M 01 01\#SelectStatsBoxDiv [accessed 2018-12-07]

5. Lee H, Kim J, Yoo R, Lee J. Development and evaluation of cardiovascular disease prevention education materials for middle-aged Korean-Chinese female workers: applying patient education materials assessment tool for printable materials (PEMAT-P). J Korean Acad Commun Health Nurs 2016;27(3):284-292 (forthcoming). [doi: 10.12799/jkachn.2016.27.3.284]

6. Lee H, Chae D, Lee K, Lee M. Experiences of middle-aged Korean-Chinese female migrant workers in Korea: with focus on risk factors in work-related musculoskeletal diseases. J Korean Acad Commun Health Nurs 2013;24(2):185-194 (forthcoming). [doi: 10.12799/jkachn.2013.24.2.185]

7. Centers for Disease Control and Prevention. 2018. Physical Activity Basics: How Much Physical Activity Do You Need? URL: https://www.cdc.gov/physicalactivity/basics/pa-health/index.htm [accessed 2019-06-07]

8. Manson JE, Greenland P, LaCroix AZ, Stefanick ML, Mouton CP, Oberman A, et al. Walking compared with vigorous exercise for the prevention of cardiovascular events in women. N Engl J Med 2002 Sep 5;347(10):716-725. [doi: 10.1056/NEJMoa021067] [Medline: 12213942]

9. Hanson S, Jones A. Is there evidence that walking groups have health benefits? A systematic review and meta-analysis. Br J Sports Med 2015 Jun;49(11):710-715 [FREE Full text] [doi: 10.1136/bjsports-2014-094157] [Medline: 25601182]

10. Peeler J, Christian M, Cooper J, Leiter J, MacDonald P. Managing knee osteoarthritis: the effects of body weight supported physical activity on joint pain, function, and thigh muscle strength. Clin J Sport Med 2015 Nov;25(6):518-523. [doi: 10.1097/JSM.0000000000000173] [Medline: 25647537]

11. Lee H, Wilbur J, Chae D, Lee K, Lee M. Barriers to performing stretching exercises among Korean-Chinese female migrant workers in Korea. Public Health Nurs 2015;32(2):112-121. [doi: 10.1111/phn.12105] [Medline: 24447032]

12. Kang K, Kim S, Kang SR, Lee S, Kim YY, Ellis KW. Development and preliminary testing of a smartphone-based injury-prevention application (S-IPA) for teachers at child-care centers in South Korea. J Community Health Nurs 2017;34(3):147-159. [doi: 10.1080/07370016.2017.1340767] [Medline: 28767294]

13. Kosse RC, Bouvy ML, de Vries TW, Kaptein AA, Geers HC, van Dijk L, et al. mHealth intervention to support asthma self-management in adolescents: the ADAPT study. Patient Prefer Adherence 2017;11:571-577 [FREE Full text] [doi: 10.2147/PPA.S124615] [Medline: 28356720]

14. Kakihara M. Think with Google. 2016 Dec. Mobile Apps in APAC: 2016 Report URL: https://www.thinkwithgoogle.com/ intl/en-apac/trends-and-insights/mobile-apps-in-apac-2016-report/ [accessed 2018-12-13]

15. Information Communication Plaza-Seoul. 2015. Report on the 2015 Living Environment Survey of Foreign Residents in Seoul URL: https://opengov.seoul.go.kr/sanction/7036771 [accessed 2019-06-03]

16. Kay M, Santos J, Takane M. World Health Organization. 2011. mHealth: New Horizons for Health Through Mobile Technologies URL: https://www.who.int/goe/publications/goe mhealth web.pdf [accessed 2019-06-07]

17. Liamputtong P, Koh L, Wollersheim D, Walker R. Peer support groups, mobile phones and refugee women in Melbourne. Health Promot Int 2016 Sep;31(3):715-724. [doi: 10.1093/heapro/dav015] [Medline: 25804668]

18. Morley D. Communications and Mobility: the Migrant, the Mobile Phone and the Container Box. London: Wiley-Blackwell; 2017.

19. Walker R, Koh L, Wollersheim D, Liamputtong P. Social connectedness and mobile phone use among refugee women in Australia. Health Soc Care Community 2015 May;23(3):325-336. [doi: 10.1111/hsc.12155] [Medline: 25427751]

20. Feurstein K, Hesmer A, Hribernik K, Thoben K, Schumacher J. Living Labs: a new development strategy. In: Schumacher J, Niitamo VP, Feurstein K, Pitkänen O, editors. European Living Labs - A New Approach for Human Centric Regional Innovation. Berlin: Wissenschaftlicher Verlag; 2008:1-14. 
21. Kim J, Kim Y, Jang H, Cho M, Lee M, Kim J, et al. Living labs for health: an integrative literature review. Eur J Public Health 2019 Jun 6. [doi: 10.1093/eurpub/ckz105] [Medline: 31169898]

22. Malmberg K, Vaittinen I. User Engagement for Large Scale Pilots in the Internet of Things. 2017. Living Labs Methodology Handbook URL: https://u4iot.eu/pdf/U4IoT_LivingLabMethodology_Handbook.pdf [accessed 2018-10-24]

23. Bartholomew LK, Parcel GS, Kok G, Gottlieb NH. Intervention Mapping: Designing Theory and Evidence-Based Health Promotion Programs. New York, US: McGraw-Hill; 2006.

24. Kress VE, Shoffner MF. Focus groups: a practical and applied research approach for counselors. J Couns Dev 2007;85(2):189-195 doi: 0.1002/j.1556-6678.2007.tb00462.x(forthcoming). [doi: 10.1002/j.1556-6678.2007.tb00462.x]

25. Cox CL. An interaction model of client health behavior: theoretical prescription for nursing. ANS Adv Nurs Sci 1982 Oct;5(1):41-56. [doi: 10.1097/00012272-198210000-00007] [Medline: 6817699]

26. Michie S, Ashford S, Sniehotta FF, Dombrowski SU, Bishop A, French DP. A refined taxonomy of behaviour change techniques to help people change their physical activity and healthy eating behaviours: the CALO-RE taxonomy. Psychol Health 2011 Nov;26(11):1479-1498. [doi: 10.1080/08870446.2010.540664] [Medline: 21678185]

27. Jin M, Kim J. Development and evaluation of an evaluation tool for healthcare smartphone applications. Telemed J E Health 2015 Oct;21(10):831-837. [doi: 10.1089/tmj.2014.0151] [Medline: 26431261]

28. Lynn MR. Determination and quantification of content validity. Nurs Res 1986;35(6):382-385. [doi: 10.1097/00006199-198611000-00017] [Medline: $\underline{\text { 3640358] }}$

29. Polit DF, Beck CT. The content validity index: are you sure you know what's being reported? Critique and recommendations. Res Nurs Health 2006 Oct;29(5):489-497. [doi: 10.1002/nur.20147] [Medline: 16977646]

30. McAuley E. The role of efficacy cognitions in the prediction of exercise behavior in middle-aged adults. J Behav Med 1992 Feb;15(1):65-88. [doi: 10.1007/BF00848378] [Medline: 1583674]

31. Marcus BH, Selby VC, Niaura RS, Rossi JS. Self-efficacy and the stages of exercise behavior change. Res Q Exerc Sport 1992 Mar;63(1):60-66. [doi: 10.1080/02701367.1992.10607557] [Medline: 1574662]

32. Lee M, Lee H, Kim Y, Kim J, Cho M, Jang J, et al. Mobile app-based health promotion programs: a systematic review of the literature. Int J Environ Res Public Health 2018 Dec 13;15(12):pii: E2838 [FREE Full text] [doi: 10.3390/ijerph15122838] [Medline: $\underline{30551555]}$

33. D'Agostino RB, Vasan RS, Pencina MJ, Wolf PA, Cobain M, Massaro JM, et al. General cardiovascular risk profile for use in primary care: the Framingham Heart Study. Circulation 2008 Feb 12;117(6):743-753. [doi:

10.1161/CIRCULATIONAHA.107.699579] [Medline: 18212285 ]

34. Michie S, Jochelson K, Markham WA, Bridle C. Low-income groups and behaviour change interventions: a review of intervention content, effectiveness and theoretical frameworks. J Epidemiol Community Health 2009 Aug;63(8):610-622. [doi: 10.1136/jech.2008.078725] [Medline: 19386612]

35. Koelet S, de Valk HA. Social networks and feelings of social loneliness after migration: the case of European migrants with a native partner in Belgium. Ethnicities 2016;16(4):610-630 (forthcoming). [doi: 10.1177/1468796816638398]

36. Phanareth K, Vingtoft S, Christensen AS, Nielsen JS, Svenstrup J, Berntsen GK, et al. The Epital Care Model: a new person-centered model of technology-enabled integrated care for people with long term conditions. JMIR Res Protoc 2017 Jan 16;6(1):e6 [FREE Full text] [doi: 10.2196/resprot.6506] [Medline: 28093379]

37. Sidhu MS, Gale NK, Gill P, Marshall T, Jolly K. A critique of the design, implementation, and delivery of a culturally-tailored self-management education intervention: a qualitative evaluation. BMC Health Serv Res 2015 Feb 7;15:54 [FREE Full text] [doi: 10.1186/s12913-015-0712-8] [Medline: 25890256]

38. Mathews E, Thomas E, Absetz P, D'Esposito F, Aziz Z, Balachandran S, et al. Cultural adaptation of a peer-led lifestyle intervention program for diabetes prevention in India: the Kerala diabetes prevention program (K-DPP). BMC Public Health 2018 Jan 4;17(1):974 [FREE Full text] [doi: 10.1186/s12889-017-4986-0] [Medline: 29298703]

39. Shilts MK, Horowitz M, Townsend MS. Goal setting as a strategy for dietary and physical activity behavior change: a review of the literature. Am J Health Promot 2004;19(2):81-93. [doi: 10.4278/0890-1171-19.2.81] [Medline: 15559708]

40. Conroy DE, Yang C, Maher JP. Behavior change techniques in top-ranked mobile apps for physical activity. Am J Prev Med 2014 Jun;46(6):649-652. [doi: 10.1016/j.amepre.2014.01.010] [Medline: 24842742]

41. Webb TL, Joseph J, Yardley L, Michie S. Using the internet to promote health behavior change: a systematic review and meta-analysis of the impact of theoretical basis, use of behavior change techniques, and mode of delivery on efficacy. J Med Internet Res 2010 Feb 17;12(1):e4 [FREE Full text] [doi: 10.2196/jmir.1376] [Medline: 20164043]

42. Hosper K, Nierkens V, van Valkengoed I, Stronks K. Motivational factors mediating the association between acculturation and participation in sport among young Turkish and Moroccan women in the Netherlands. Prev Med 2008 Jul;47(1):95-100. [doi: 10.1016/j.ypmed.2008.02.024] [Medline: 18378289]

43. O'Driscoll T, Banting LK, Borkoles E, Eime R, Polman R. A systematic literature review of sport and physical activity participation in culturally and linguistically diverse (CALD) migrant populations. J Immigr Minor Health 2014 Jun;16(3):515-530. [doi: 10.1007/s10903-013-9857-x] [Medline: 23771744]

44. Daniel M, Wilbur J. Physical activity among South Asian Indian immigrants: an integrative review. Public Health Nurs 2011;28(5):389-401. [doi: 10.1111/j.1525-1446.2010.00932.x] [Medline: 22092422] 
45. Gerber M, Barker D, Pühse U. Acculturation and physical activity among immigrants: a systematic review. J Public Health 2012;20(3):313-341 (forthcoming). [doi: 10.1007/s10389-011-0443-1]

46. Lee H, Cho S, Wilbur J, Kim J, Park C, Lee Y, et al. Effects of culturally adaptive walking intervention on cardiovascular disease risks for middle-aged Korean-Chinese female migrant workers. Arch Environ Occup Health 2017 Nov 2;72(6):317-327. [doi: 10.1080/19338244.2017.1282847] [Medline: 28098504]

\author{
Abbreviations \\ BCT: behavior change technique \\ IMCHB: Interaction Model of Client Health Behavior \\ KC: Korean-Chinese \\ LLm Health: living lab for a mobile-based health \\ mHealth: mobile health \\ SNS: social networking service
}

\author{
Edited by G Eysenbach; submitted 05.07.19; peer-reviewed by G Fico, B Merino; comments to author 19.08.19; revised version \\ received 04.09.19; accepted 23.09.19; published 08.01.20 \\ Please cite as: \\ Kim Y, Lee H, Lee MK, Lee H, Jang $H$ \\ Development of a Living Lab for a Mobile-Based Health Program for Korean-Chinese Working Women in South Korea: Mixed \\ Methods Study \\ JMIR Mhealth Uhealth 2020;8(1):e15359 \\ URL: https://mhealth.jmir.org/2020/1/e15359 \\ doi: $10.2196 / 15359$ \\ PMID: $\underline{31913134}$
}

(C)Yulim Kim, Hyeonkyeong Lee, Mi Kyung Lee, Hyeyeon Lee, Hyoeun Jang. Originally published in JMIR mHealth and uHealth (http://mhealth.jmir.org), 08.01.2020. This is an open-access article distributed under the terms of the Creative Commons Attribution License (https://creativecommons.org/licenses/by/4.0/), which permits unrestricted use, distribution, and reproduction in any medium, provided the original work, first published in JMIR mHealth and uHealth, is properly cited. The complete bibliographic information, a link to the original publication on http://mhealth.jmir.org/, as well as this copyright and license information must be included. 